\title{
USAGE OF ENERGY HARVESTING TECHNOLOGY IN AMPHIBIOUS ALL-TERRAIN VEHICLE
}

\author{
(C) Vitaliy Krupenin ${ }^{1}$, George Nerubenko², Pavel Kolomier $^{3}$ \\ ${ }^{1}$ IMASH RAN, Moscow, Russia \\ krupeninster@gmail.com \\ ${ }^{2} \overline{N E R * M A R \text { Limited, Canada }}$ \\ optimalproject@hotmail.com \\ ${ }^{3} P K \& M M$ Engineering Ltd, Canada \\ pk6662041@gmail.com
}

\begin{abstract}
All amphibious all-terrain vehicle components including its chassis are subjected to harsh vibrations during driving. This paper explores the system of newly patented Vibration Energy Harvesting Dampers for mitigation of such vibrations is used because it could provide mutually interconnected results: reduction of undesired vibration levels and generating of additional electrical power. The examples of their installations into driveline and chassis structures are studied.
\end{abstract}

Keywords: amphibious all-terrain vehicle, vibration energy harvesting damper.

\section{ИСПОЛЬЗОВАНИЕ ТЕХНОЛОГИИ ПРЕОБРАЗОВАНИЯ ЭНЕРГИИ В ВЕЗДЕХОДАХ}

\author{
(C) Виталий Львович Крупенин ${ }^{1}$, Георгий Петрович Нерубенко른 \\ Павел Коломиер ${ }^{3}$ \\ ${ }^{1}$ Институт машиноведения им. А.А. Благонравова, Москва, Россия \\ krupeninster@gmail.com \\ ${ }^{2}$ NER*MAR Limited, Канада \\ optimalproject@ hotmail.com \\ ${ }^{3}$ PK\&MM Engineering Ltd, Kaнada \\ pk6662041@gmail.com
}

\begin{abstract}
Аннотация. Все компоненты, включая шасси, гусеничных вездеходов подвержень экстремальным вибрациям во время движения. В статье рассмотрено использование системы новых запатентованных вибрационных энергособирающих демпферов для устранения таких вибраций, т.к. эта система может обеспечить взаимосвязаннье результаты: снижение нежелательных вибрационных уровней и генерирование дополнительной электроэнергии. Рассмотрень примеры их установки в конструкцию привода и шасси.
\end{abstract}

Ключевые слова: гусеничный вездеход, вибрационный энергособирающий демпфер. 
The severe vibration fields are a problem for the all-terrain amphibian vehicles during operation in agricultural environment. The study of vibration suppression combined with parallel generation of electrical power (energy harvesting) using suppressed vibrations is presented. New midsize allterrain amphibian vehicle is an object of study. The accumulated experience demonstrates that the harshest vibrations are registered in a driveline and a chassis. The today technology is widely using the energy harvesting units having a certain oscillating weight allowing (in parallel to vibration mitigation) capture, convert and transfer some amount of wasted power [1],[2],[4],[5],[8],[11],[12]. Energy harvesting is used in particular for feeding autonomous electronic devices in vehicles. The authors invented and developed Vibration Energy Harvesting Dampers (VEHD) [3], [6] consisting of tuned mass damper (TMD) and an alternator or generator of electricity. The detailed analysis of a various published materials regarding VEHD is not a subject of the study and authors decide to concentrate only on own results. The specific of proposed VEHD is to provide self-tuning to dampen harmonics over a wide interval of fluctuated frequencies using the control system of TMD. The implementation of VEHD in all-terrain amphibian vehicles was dictated by two combined reasons: necessity of a reduction of intensive vibrations and proper usage of damped vibration energy while the vehicle engine is operating in a significantly broad interval of changing RPM.

A necessity to avoid intensive vibration problems during off-road exploiting of amphibian allterrain vehicles in rural /agricultural areas brings new ideas in schematic composition of such vehicles. The authors developed new vehicle using some conceptual of track loader design described in [7] (see Fig. 1).

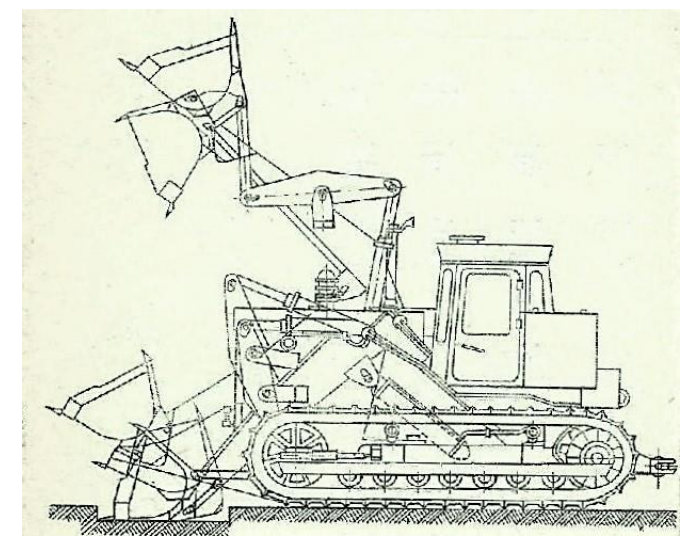

Fig. 1. Track loader with $102.9 \mathrm{~kW}$ engine [7].

The new vehicle has the same platform concept. However, it is obvious that new parameters were improved and differed from data issued in [7]. The platform design could be used in several modifications. The authors designed it in form of an amphibian all-terrain vehicle (see photo in Fig.2).
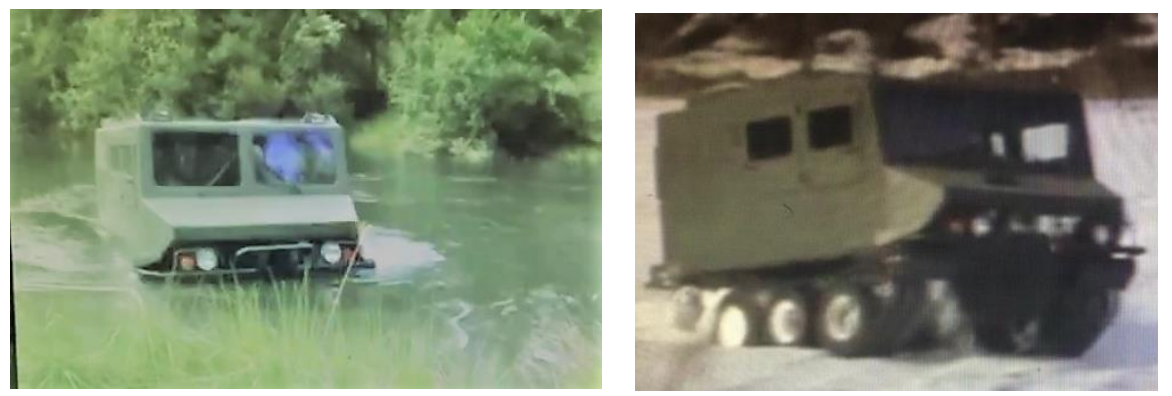

Fig. 2. Amphibious all-terrain track "WOODDZOR" 
Its general specification is - length $3.8 \mathrm{~m}$, width $2.4 \mathrm{~m}$, height $2.15 \mathrm{~m}$; the equipped weight $=1850$ $\mathrm{kg}$, and the total weight $=2600 \mathrm{~kg}$; passenger capacity $=6$ people and $150 \mathrm{~kg}$ of cargo or $750 \mathrm{~kg}$; engine (1.5-litre, Gasoline, 4-cylinder) completed with six-speed automatic transmission; power in range of $120 \mathrm{~kW}-140 \mathrm{~kW}$; maximum speed on land $=60 \mathrm{~km} / \mathrm{hr}$; the speed on the water $=6 \mathrm{~km} /$ $\mathrm{hr}$; fuel tank $=130$ litres. The vehicle could be equipped by loading/transporting units or other devices. It is the all-season vehicle ready to overcome small river, lake, marsh, snow, and other agricultural circumstances. It was established that a driveline and chassis were the most problematic units of vehicle from vibration point of view. Driveline consists technically of two major units: an engine and a transmission. The torsional vibrations of crankshaft (in engine) and various geared shafts (in transmission) are regular problems for a driveline. The rectilinear vibrations are the problems for the transmission body and a chassis.

The authors proposed invented universal tool for suppression of different types of vibrations based on VEHD [3], [6]. VEHD could be presented in two general versions: "angular - torsional operation" and "rectilinear vibration operation". The detailed scheme descriptions, kinematic and dynamic analysis of VEHD used in engine are described in [4], [6] and [10]. Let's apply now the same approach for suppression of torsional vibrations occurred in transmission.

The general model of a transmission is shown in left part of Fig. 3. The model contains a transmission, completed with a flywheel on the entrance end and VEHD on the exit end. A flywheel and VEHD are rotating at starting point with angular speed $\omega$. A transmission has a system of geared shafts modelled by coil spring connecting flywheel and VEHD. It is assumed that solid part 1 (see a scheme in right side of Fig.3) of VEHD mounted on exit shaft. The mass 3 of TMD is attached to hub of VEHD solid part 1 by means of spring 2, so the mass could move in $Z$ direction. Actually there are several masses located in the symmetrical way for avoiding the dynamic unbalance, and they are composing torsional vibration damper.

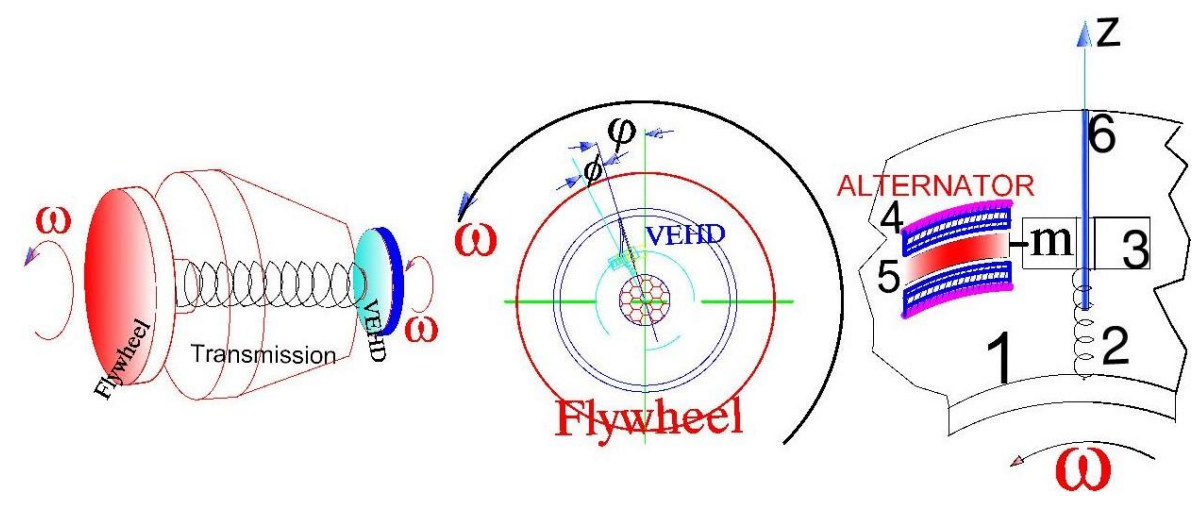

Fig. 3. Modelling of a system "flywheel - transmission - VEHD"

A mass 3 is mounted freely on beam 6 (cantilever spring), which is connected to outer ring of 1, but is free at the near hub end of 1 , so between hub and spring 6 there is a gap. A mass 3 is moving along beam 6 . Hence, mass 3 could move in radial direction using beam 6 and oscillating across clamp point of beam 6 to rim. The position of mass 3 is dictated by balance of two forces: centrifugal force (trying to move mass 3 to periphery) and force of spring 2 compression (trying to keep mass 3 close to hub). As the radial position of the mass 3 is extended, the length of cantilever spring 6 for providing bending beam resistance is effectively shortened. The shortening of the beam, in turn, implies a greater perpendicular force, for a perpendicular displacement i.e. as the length of the bending beam is shortened, the spring constant of proportionality relating displacement to force 6 increases. These effects, the outward displacement of mass 3 under angular 
velocity and the corresponding increase of the spring constant of proportionality 6 as the masses 3 move outward result in reducing of oscillations over the operating range of $\omega$.

The solid part of VEHD is vibrating in the same direction as a flywheel, and its displacement coordinate against flywheel is $\varphi(t)$, where $t$ is time (see central part of Fig. 3). A mass 3 is connected to magnet 5 which is displacing in coils 4 (coils 4 and magnets 5 are the alternator portion of VEHD). The angular coordinate of vibrations of damper mass 3 with magnet 5 vs. solid parts of VEHD is $\phi(t)$. The invented device allows keep automatically the natural frequency $\omega_{0}$ equals to $\omega^{2}=k_{1} / j=\omega_{0}{ }^{2}$, where $k_{1}$ is the current stiffness coefficient of springing elements 6 and $\mathrm{j}$ is mass moment of inertia of all masses 3 coupled to magnets 5 presenting the VEHD.

Suppose that $\mathbf{J}$ is a mass moment of inertia of all parts located between flywheel and torsional vibration damper (consisting of masses 3 and magnets 5) which is a mechanical component of VEHD. The stiffness properties of a system of geared shafts modelled by coil spring are modelled by stiffness coefficient matrix $k$ and viscous friction matrix coefficient of loss $b$.

The movable parts of VEHD are connected to solid parts of VEHD by means of springs having the stiffness $k_{1}=j \omega^{2}$ and viscosity factor $b_{1}$. The simplified system of ordinary differential equations for system "transmission - VEHD" could be written in similar way to a system presented in [1], [2], [4], [5], [9], [10], [11], [12]. The external force would be presented by $H \sin \omega t$, where $H$ is the magnitude of external force, $\omega$ is the frequency of external force. The displacements masses 3 can be ignored for stable regime with constant $\omega$ at considered moment. Regarding alternator portion of VEHD: its electromagnetic subsystem is inducing current $\mathrm{i}$, and $\mathrm{L}$ is inductance, $R$ is electrical resistance, where $R_{c}$ is coil resistance and $R_{\mathrm{d}}$ is load resistance, and $R=R_{\mathrm{c}}+R_{\mathrm{d}}$. Hence:

$$
\begin{gathered}
J \ddot{\varphi}+b_{1}(\dot{\varphi}-\dot{\phi})+j \omega^{2}(\varphi-\phi)+b \dot{\varphi}+k \varphi=H \sin \omega t \\
j \ddot{\phi}-b_{1}(\dot{\varphi}-\dot{\phi})-j \omega^{2}(\varphi-\phi)+F i=0, \\
L \dot{i}+R i-F(\dot{\phi}-\dot{\varphi})=0,
\end{gathered}
$$

where ${ }^{\prime}=d / d t$, and $F$ - linkage factor.

The linkage factor could be determined in most cases as $F=B L_{\mathrm{s}}$, where $B$ is field flux and $L_{\mathrm{s}}$ is characteristic size. The structure of equation (1) in a system (1) - (3) is reflected the fact that a transmission is considered like one-degree-of-freedom subsystem. It should be changed when the examined subsystem could be identified as multi-degree-of-freedom subsystem, for instance, twodegree-of-freedom subsystem; in that case of two-degree-of-freedom an equation (1) would be split on two equations.

Before starting the numerical simulation analysis, the peak-to-peak twist angles of the real six-speed automatic transmission were recorded for running vehicle at $50 \mathrm{~km} / \mathrm{hr}$.

The preliminary recorded peak-to-peak twist angles of a transmission are presented in Figure 4A, where abscissa axis is the frequencies in $\mathrm{Hz}$, and on ordinate axis the $2 \varphi$ torsional peak-to-peak exit end angle vibration values (in degrees) are shown. The range of interest $20 \mathrm{~Hz}-70 \mathrm{~Hz}$ was selected taking into an account the results of preliminary estimates of transmission low mode resonance frequencies by FEM.

The analysis of obtained data shows that there are several spikes of twist angles; however the biggest values of recorded peak-to-peak twist angle are 1.256 degrees at $52.5 \mathrm{~Hz}$ and 0.623 degrees at $63 \mathrm{~Hz}$. The recorded values are higher than required 0.4 degrees [10]. Hence, it could be suggested that for modelling purposes it would be possible to use two degree-of-freedom model for considering torsional vibrations in transmission. 
www.vntr.ru

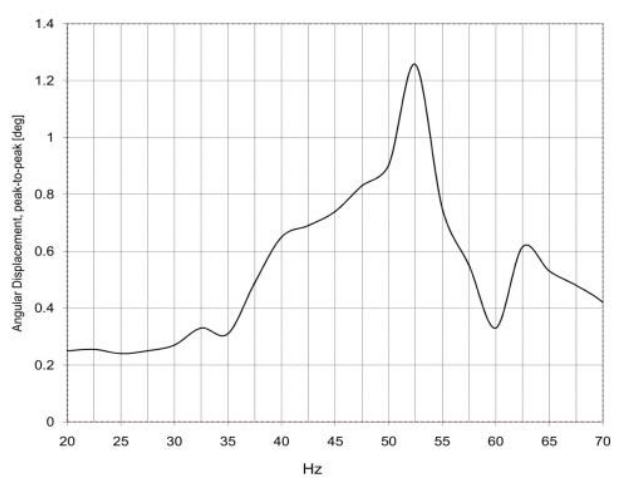

A
№ 5 (141), 2019 год

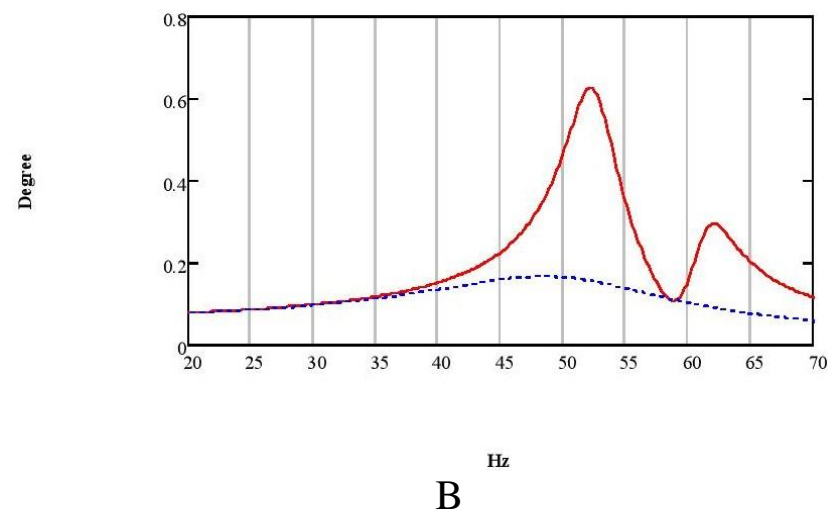

Fig. 4. A- Recorded Peak-to-Peak Twist Angles of tested transmission. B-Angular amplitudefrequency characteristics for torsional vibrations of transmission.

Now the transmission torsional vibration model is presented by two degree-of-freedom subsystem, it means that equation (1) is split into two interconnected equations (1A) and (1B); the torsional vibration damper component and alternator would be presented formally by equations (2) and (3). The selection of a model parameters is dictated by the following circumstances: the shape of the angular amplitude - frequency characteristic must be close to shape of recorded graph of the peakto-peak twist angles (Fig. 4A), and maximal recorded peak on Figure 4A must coincide to modelled peak. Using these criteria it is possible build the angular $(\varphi)$ amplitude - frequency characteristic as shown in Figure 4B by red solid curve. The abscissa horizontal axis is for excitation frequency in $\mathrm{Hz}$ and ordinate vertical axis in Figure 4B is for angle amplitude in degrees. Actually the red curve reflects the original system dynamical behaviour (no VEHD installed). Analyzing the amplitude frequency characteristic for that system in Figure 4B, it is obtained that the peak amplitude of 0.628 degrees is presented at excitation frequencies equals to $52.5 \mathrm{~Hz}$; it is equivalent to spike of $2 \varphi$ in Figure 4A. The second spike of 0.308 degrees is located at $62 \mathrm{~Hz}$. One can state that the selected model of the transmission torsional vibrations is equivalent to real low frequencies mechanism.

The obtained data were used for designing of VEHD applicable for that specific transmission. Also it was assumed that the mass moment of inertia $j$ of movable parts of VEHD $j=0.018 J$. Let's suppose for simplicity that the initial parameters of an alternator for trial study are selected following the recommendations [4], [5]. The theoretical angular amplitude - frequency characteristic of a transmission equipped by such VEHD is shown in Figure 4B by the blue dotted curve. The peak of damped torsional vibration curve is equal to 0.168 degrees at $49 \mathrm{~Hz}$. No other peaks are for this curve. Now the maximal peak-to-peak twist angle $(2 \varphi)$ is equal to 0.336 degrees. So for total range of operating RPM (frequencies) the torsional vibrations of engine shaft completed by VEHD are low than the torsional vibrations of engine shaft without VEHD.

Thinking about reduction of torsional vibration level at initial resonance $(52.5 \mathrm{~Hz})$, one can see that the amplitude of system with VEHD at $52.5 \mathrm{~Hz}$ is equal to 0.157 degrees now, so the rate of amplitude reduction at initial system resonance (@ $52.5 \mathrm{~Hz}$ ) is 4 times. VEHD maximum induced power would be equal to 62.21 Watt.

The prototype of proposed transmission VEHD was designed, fabricated, assembled and tuned (see photo of the prototype presented in Fig. 5A). The recorded peak-to-peak twist angles of a transmission with VEHD are presented in Figure 5B, where abscissa and ordinate axis are similar to a plot in the Fig 4A. The analysis of these graph shows that there is one peak of twist angles -0.367 degrees at $48 \mathrm{~Hz}$. The maximum recorded induced electrical power is 59 Watt. The obtained results prove the accuracy of selected modelling. 


\section{Bulletin of Science and Technical Development}

www.vntr.ru

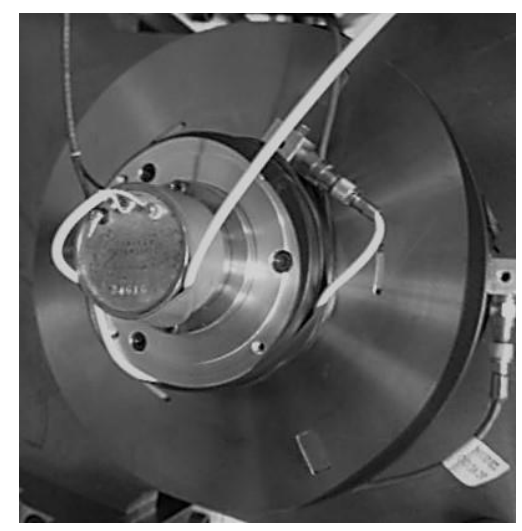

A
№ 5 (141), 2019

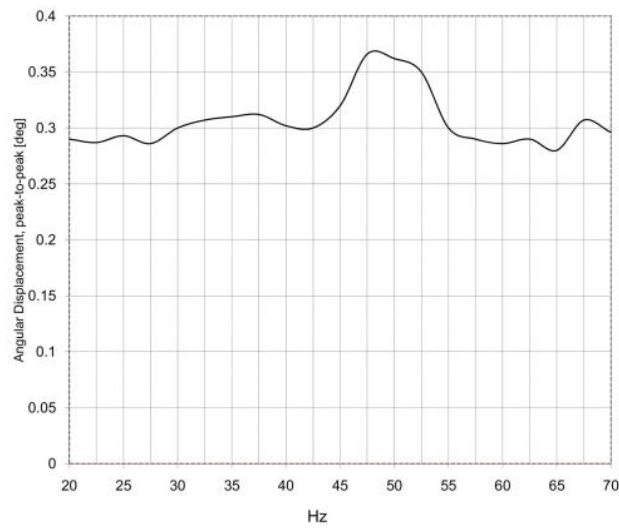

B

Fig. 5. A-Transmission VEHD. B- Recorded Peak-to-Peak Twist Angles of transmission with VEHD

The similar approach was applied for suppression on engine crankshaft torsional vibrations. The prototype incorporated the features and properties of the angular torsion version of VEHD was developed, manufactured and installed on front end of engine shaft. The operation range of rpm for the engine was $800-5,000$. The concerned resonance was recorded on a graph for $6^{\text {th }}$ order torsional vibrations at $4100 \mathrm{rpm}$ with peak - to - peak angle of 1.002 degrees. It means that actual crankshaft torsional vibrations with 1.002 degrees (despite of presence of regular Torsional Vibration Damper) were at $\omega=4100(\mathrm{rpm}) \times 6($ order $) \times \pi / 30=2574.81 / \mathrm{sec}=410 \mathrm{~Hz}$. The installation of VEHD leads to the following results: now there are $6^{\text {th }}$ order resonance torsional vibrations @ 3550 RPM with peak - to - peak angle of 0.127 degrees. It is significantly lower than the industrial requirement of 0.4 degrees. The maximal value of recorded generated power was very small $1.1 \times 10^{-3}$ Watt.

For mitigation of undesired chassis vertical vibrations it was designed the rectilinear version of VEHD. The differences between "angular - torsional operation" version of VEHD and "rectilinear vibration operation" version are: 1 . formally the rectilinear model has masses $\mathrm{M}$ and $\mathrm{m}$ instead of masses moment of inertia $\mathrm{J}$ and $\mathrm{j}$ in equations $(1)-(3)$; 2 . the rectilinear version must be equipped by additional control system for keeping $\omega^{2}=k_{1} / m=\omega_{0}^{2}$.

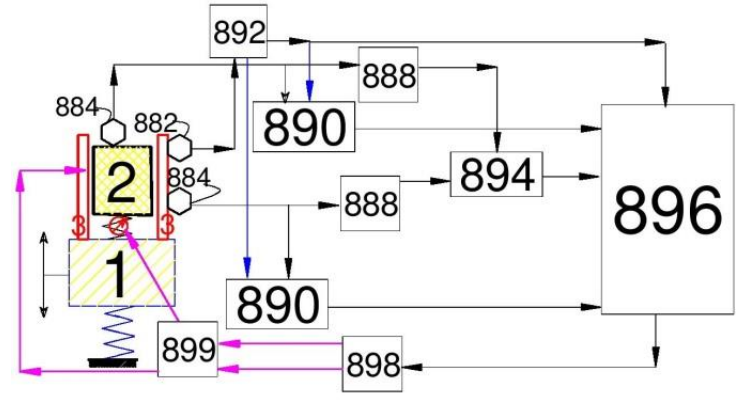

Fig. 6. Schematic diagram of electromagnetic apparatus version for rectilinear VEHD

The Fig. 6 shows one of the schematic diagrams of an electromagnetic apparatus $\mathbf{8 0 0}$ for providing feedback to dynamic system 1-2-3 for keeping $\square^{2}=k_{1} / m=\square^{2}$. Accelerometers 884 are connected to 2 - TMD and to 3 - electromagnetic solenoid (shown in cross section). The accelerometers $\mathbf{8 8 4}$ are each connected to integrators $\mathbf{8 9 0}$. Both outputs of integrator $\mathbf{8 9 0}$ are connected to computing 
system 896. The accelerometers $\mathbf{8 8 4}$ are also connected to phase detectors $\mathbf{8 8 8}$ that are, in turn, connected to one phase discriminator $\mathbf{8 9 4}$. This is, in turn, connected to the computing system $\mathbf{8 9 6 .}$ Also connected to the solenoid is a frequency detector $\mathbf{8 8 2}$ that is connected, via filter $\mathbf{8 9 2}$, to the integrators 890 and the computing system 896. Amplifiers and filters may be used, where needed for ensuring the proper signal transmission. The computing system is connected to a signal generator 898, which is connected to the actuator of springing element (located between 1 and 2) and solenoid 3. The computing system 896 has the capacity to (i) input frequency, amplitude and phase difference data, (ii) perform algorithms on this data, and (iii) generate command signals to govern VEHD. The computing system 896 accommodates the designed algorithm, which provides self-tuning.

The prototype of VEHD focused on extracting the possibly maximum power from vibrating chassis was designed and fabricated. The fragment of a control system for rectilinear VEHD installed on chassis is shown in Figure 7.

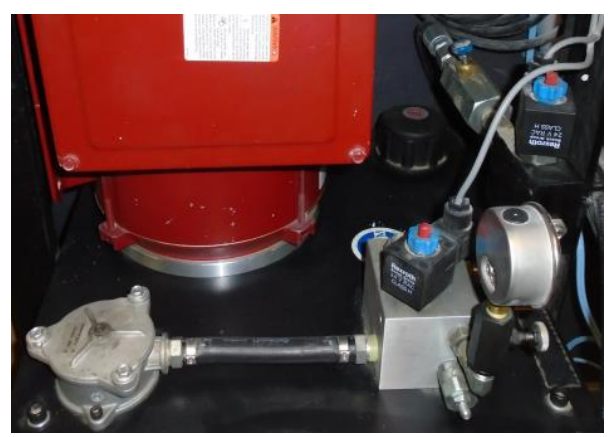

Fig. 7. Fragment of control system for rectilinear VEHD installed on chassis

The design parameters were composed specifically for prototype mounting on a chassis vibrating in range of $16.5 \mathrm{~Hz}-25 \mathrm{~Hz}$. The selected mass of fabricated TMD part in VEHD was 1/6 of model mass or $1.05 \mathrm{~kg}$. All other main characteristics were based on values relatively presented in considered modelling case. Six units of VEHD were vertically installed close to perimeter of a chassis. The comparison of values recorded in the tests to data obtained in previous theoretical study was done. It is necessary to underline at this moment that it would be expected that six properly located equal-size distributed VEHD of fabricated mass of $1.05 \mathrm{~kg}$ should substitute one VEHD having mass of $6.3 \mathrm{~kg}$. The measured maximum amplitude of chassis vibrations before installation of VEHD was registered at $3.8 \mathrm{~mm}$. The measured maximum amplitude of chassis vibrations with assembled VEHD was $2.4 \mathrm{~mm}$. The recorded average magnitudes of useful powers of each of six VEHD were summarised and result was $2.47 \mathrm{~kW}$. It is around $2 \%$ of working engine power. It could be point out that the presented configuration of VEHD is not restricted, and VEHD could be applicable in various situations in all types of vehicles. All types of vehicles have more or less similar problems with chassis because of intensive agricultural loads. Hence, all chassis need to be equipped by newly designed VEHD.

\section{Conclusions}

1. The effective protection of all-terrain amphibian vehicle major components such as the engine, a transmission and chassis from severe vibrations combined with obtaining the additional electrical power would be reached by implementation of patented VEHD. The elaborated VEHD has several improved features being installed on the selected unit of all-terrain 
amphibian vehicles exploiting in agriculture. The universality of application of proposed schemes is one of the most important issues among others.

2. There could be the recommendation regarding usage of VEHD specifically in the agricultural amphibian all-terrain vehicles: implement VEHD focused on the effectiveness of using wasted power for obtaining additional portion of electrical power.

3. The developed VEHD should be installed and used successfully in various types of vehicles. The proposed VEHD could be used for feeding autonomous electronic devices and/or charging on-board battery.

\section{References}

1. Priya, S and D. L, Inman, Energy Harvesting Technologies. Sprinder. Verlag. (2009).

2. Cottone, F, Energy Harvesting: introduction in NiPS Summer School, Fiuggi (Italy), 50 p. (2015).

3. Nerubenko et al. Vibration Energy Harvesting Damper. U.S. Patent Application No. 16/119,346, (2018).

4. Bograd, A, Nerubenko, G, Nerubenko, C. Energy Harvesting in Vehicle's Drive. Proceedings of the 2nd International Conference of Energy Harvesting, Storage, and Transfer (EHST'18). Niagara Falls, Canada, Paper No. 112 (2018).

5. Nerubenko et al. Tuned mass dampers as energy harvesters for railways. Proceedings of ISMA2018 and USD2018. Leuven, Belgium. pp. 1689-1702 (2018)

6. George Nerubenko. "Torsional Vibration Damper of a Rotating Shaft". US Patent 7,464,800. Dec. 16, 2008.

7. Нерубенко Г. П., Ватипко Б. А., Щур П. А., Справочник по перегрузочному оборудованию на морском транспорте (The handbook of loading equipment in marine transport). / 221 с. ил. - Одесса: Маяк, 1990.

8. Cottone, F., Goyal, S., Punch J., Energy harvester apparatus having improved efficiency. US Patent 8,350,394. January 8, 2013.

9. Nerubenko G., Krupenin V., Nerubenko C. Vehicle Hybrid Free - Piston Engine - Generator. $16^{\text {th }}$ International Scientific Conference "ENGINEERING FOR RURAL DEVELOPMENT". Proceedings. Jelgava, Latvia, May 24.-26, 2017. P. 114-120.

10. Nerubenko G. Tuned Torsional Vibration Damper. SAE Technical Paper 2013-01-1897, 2013, doi:10.4271/2013-01-1897.

11. Nerybenko G. Vibration Energy Harvesting Damper in Vehicle Driveline. SAE Technical Paper 2019-01-0782, 2019, doi:10.4271/2019-01-0782.

12. Nerubenko, G., Gurevych, D., and Kolomier, P., Dynamics of Amphibious All-Terrain Vehicle's Chassis Having Vibration Energy Harvesting Dampers. SAE Technical Paper 201901-1510, 2019, doi:10.4271/2019-01-1510.

Дата поступления: 5 мая 2019 г. 